\title{
LA RESPONSABILIDAD SOCIAL COMO IMPERATIVO EN LA CONSTITUCIÓN ECONÓMICA PERUANA
}

\author{
María Elena Guerra-Cerrón* \\ Universidad de Lima, Lima, Perú \\ meguece@yahoo.com.mx \\ Recibido: 18/1/2021 Aprobado: 25/1/2021 \\ doi: https://doi.org/10.26439/iusetpraxis2021.n052.5065
}

\begin{abstract}
RESUMEN. El deber de realizar las actividades económicas con responsabilidad social en el Perú se establece en la Constitución económica, y no solo comprende a las actividades del poder privado, sino también a las del poder público en el marco de la llamada economía social de mercado. Por tanto, es incomprensible que este deber se considere como una facultad y se deje su cumplimiento a la libre voluntad. En este artículo se explicará que la responsabilidad social es un componente esencial del régimen económico nacional y, por ende, se encuentra prevista de manera implícita en la Constitución Política del Perú. La denominación apropiada y omnicomprensiva debería ser economía de mercado con responsabilidad social, de tal modo que la responsabilidad social pase de verse como una facultad a aceptarse como un imperativo constitucional de obligatorio cumplimiento.
\end{abstract}

PALABRAS CLAVE: Constitución Política / actividad económica / economía social de mercado / Constitución económica / responsabilidad social

\footnotetext{
* Abogada por la Pontificia Universidad Católica del Perú. Magíster en Derecho Empresarial por la Universidad de Lima. Doctora en Derecho y Ciencia Política por la Universidad Nacional Mayor de San Marcos. Estudios de especialización en Contratación Moderna y Responsabilidad Civil en las Universidades de Castilla-La Mancha y Salamanca en España. Docente en la Universidad Nacional Mayor de San Marcos en pregrado y posgrado, y en la Universidad de Lima. Miembro del Instituto Iberoamericano de Derecho Procesal y del Instituto Peruano de Derecho Mercantil. Estudios de maestría en Derecho Procesal Constitucional, Universidad Lomas de Zamora, Buenos Aires. Fue juez civil de la Corte Superior de Justicia de Lima. Fiscal superior civil del DF Callao.
} 


\title{
SOCIAL RESPONSIBILITY AS AN IMPERATIVE IN THE PERUVIAN ECONOMIC CONSTITUTION
}

\begin{abstract}
The Peruvian Economic Constitution establishes the duty to carry out economic activities with social responsibility, which include not only private sector activities but also those of the public sector within the framework of the so-called "social market economy." Hence, it is impossible to comprehend that this duty is considered as a power and its fulfillment is left to free will. This article will explain that social responsibility is an essential component of the Peruvian economic system and, therefore, is implicitly provided for in the Political Constitution of Peru. The appropriate and comprehensive denomination should be "market economy with social responsibility," so that social responsibility goes from being considered as a power to being accepted as a constitutional duty of mandatory compliance.
\end{abstract}

KEYWORDS: Political Constitution / economic activity / social market economy / Economic Constitution / social responsibility 


\section{INTRODUCCIÓN}

El derecho fundamental relevante para presentar el tema de este artículo es que las personas (naturales y jurídicas) pueden participar, en forma individual o asociada, en la vida política, económica, social y cultural de la nación, a partir de lo cual se identifican diferentes ámbitos que tendrán una regulación independiente en la Constitución Política. Si bien son diferentes ámbitos con marcos legales propios: político, social (cultural) y económico, todos están vinculados por un objetivo común que es la realización de los derechos de las personas, esto es, la materialización de sus derechos objetivos de forma directa o con la intervención del órgano jurisdiccional brindándose tutela.

En este contexto, el Estado, que es una sociedad organizada, tiene un papel fundamental y constituye

[una] forma de orden político, característica de las sociedades modernas, fundada en el monopolio de la coacción sobre un determinado territorio por parte de una jerarquía burocrática, policial-militar, jurídica e impositiva [...] condición necesaria para el surgimiento del Estado fue el surgimiento de la moderna "sociedad civil", concepto complementario al de Estado. (D'Auria, 2012, p. 47)

En tal sentido, el Estado es el garante de la realización de los derechos y lo es de acuerdo con los mandatos de la Constitución Política, que puede ser considerada como una "gran hoja de ruta" para la convivencia en una sociedad organizada. El profesor Marcial Rubio Correa (2006) la describe de la siguiente manera:

Tras el ropaje técnico y jurídico consustancial a su naturaleza, toda Constitución es en realidad una opción política. [...] En su texto constitucional (Constitución escrita formal) y, en su implementación cotidiana (Constitución real), cada Estado recoge un conjunto de ideas predominantes y también un conjunto de prácticas sociales, que definen las reglas de funcionamiento de la sociedad en sus aspectos políticos, sociales y económicos. (p. 99)

Así, la Constitución Política como "hoja de ruta nacional" contiene las reglas de funcionamiento de la sociedad en tres dimensiones principales (que son precisamente aquellas en las que las personas naturales o jurídicas se realizan en sus diferentes actividades y derechos): política, social (cultural) y económica. Si bien las reglas están establecidas en secciones separadas, deben ser leídas en forma concordada y armónica, puesto que el propósito es promover y alcanzar el bienestar general que se fundamenta en la justicia y en el desarrollo integral y equilibrado, como deber primordial del Estado democrático de derecho (dimensión política), según se establece en los artículos 43 y 44.

La sociedad debe estar organizada en un Estado de derecho. Históricamente este fue mal concebido como un Estado de la ley o Estado legal. Esta situación llevó a la aparición del fenómeno de la "constitucionalización de los derechos", lo que dio paso al denominado Estado constitucional de derecho, para "Ilamar la atención" sobre el hecho de que la 
unidad del derecho o sistema u ordenamiento jurídico recae en la Constitución Política, con el efecto de una nueva forma de concebirla al interpretar y aplicar el derecho, como bien ha sido explicado por el Tribunal Constitucional peruano:

El tránsito del Estado legal de derecho al Estado constitucional de derecho supuso, entre otras cosas, abandonar la tesis según la cual la Constitución no era más que una mera norma política, esto es, una norma carente de contenido jurídico vinculante y compuesta únicamente por una serie de disposiciones orientadoras de la labor de los poderes públicos, para consolidar la doctrina conforme a la cual la Constitución es también una norma jurídica, es decir, una norma con contenido dispositivo capaz de vincular a todo poder (público o privado) y a la sociedad en su conjunto. (STC. Exp. N. ${ }^{\circ}$ 5854-2005-PA/TC-Piura, 2005, fundamento jurídico 3)

Cabe considerar a la denominación de Estado constitucional de derecho como una reivindicación del Estado de derecho, ya que no puede existir un espacio o ámbito en la sociedad fuera de los alcances de la Constitución Política. Así, si bien puede reconocerse la libertad como principio y fundamento de la actividad del sector privado, no hay autonomía privada al margen de la Constitución Política, ni hay libertad de contratación cual "autorización en blanco". Lo antes señalado, que parecería una simple y lógica afirmación, puede serlo en teoría, mas no en la práctica; por ello resulta complejo, en especial, en cuanto al componente de la responsabilidad social en la dimensión económica. Por tanto, de las tres dimensiones de la responsabilidad social, se desarrollará la económica por su incidencia en las demás dimensiones. No pretende señalarse que la realización de los derechos políticos y sociales depende solo de la actividad económica; pero sí puede admitirse que hay una correlación directa entre ellas.

\section{RÉGIMEN ECONÓMICO PERUANO}

\section{Constitución de la República del Perú de 1979}

El antecedente de la economía social de mercado en un texto constitucional se encuentra en la Constitución de la República del Perú de 1979, en el Título III: Del régimen económico. En el Capítulo I, se establecieron principios generales y se señaló expresamente en el artículo 115 que la iniciativa privada es libre y se ejerce en una economía social de mercado, además de otros principios. También se incorporaron principios para la actividad económica en el Capítulo IV: De la empresa, en el que, por ejemplo, se reconoce la libertad de comercio e industria y se prohíben los monopolios, los oligopolios, entre otros.

\section{Constitución Política de 1993}

Como se ha señalado, la elección o determinación de la economía social de mercado como régimen económico nacional data de 1979, y más allá de la discrepancia que se pueda 
tener respecto a la Constitución peruana - precisamente en los actuales momentos en que algunas personas piden una nueva Constitución Política-, es de destacar que este régimen "en la letra" es apropiado, solo que en la práctica no se aprecian los resultados por el papel que realizan los agentes económicos y el propio Estado. En la Constitución vigente hay un espacio especial y ordenado donde se establecen las reglas de funcionamiento para la dimensión económica, y esta es la Constitución económica.

\section{LA CONSTITUCIÓN ECONÓMICA}

La Constitución económica es la parte de la Constitución Política que contiene el conjunto de normas económicas que, a decir de Gutiérrez Camacho (2013), constituye un “[...] sistema constitucional económico, pues esta expresión da cuenta de una manera más cabal de que las normas económicas constitucionales se encuentran vinculadas y son parte de un todo armónico" (p. 6).

Es necesario señalar la relevancia del término sistema en la expresión "sistema constitucional económico", en el sentido de "[...] normas orientadas a establecer las pautas básicas sobre las que debe fundarse el régimen económico de una sociedad" (STC. Exp. N. ${ }^{\circ}$ 0008-2003-Al/TC, 2003, fundamento jurídico 3), ya que se trata de un conjunto de elementos relacionados entre sí para un fin común, enfoque importante para garantizar la armonía en el propio sistema constitucional económico. El concepto de "todo armónico" en la interpretación y aplicación de las normas se extiende a las otras dos dimensiones: política y social, por la interrelación con el sistema constitucional económico. A ello hay que agregar lo siguiente:

[...] ningún ámbito de la Carta Fundamental es ajeno a los criterios interpretativos expuestos, menos aún las normas que dan forma y sustancia a lo que se ha convenido en denominar "Constitución económica". Y es que dichas disposiciones suponen el establecimiento de un plexo normativo que tiene como finalidad configurar el ámbito jurídico en el cual se desarrollará la actividad económica de nuestro país, y su propósito es que la actuación del Estado y los ciudadanos sea coherente con la naturaleza y los fines del Estado social y democrático de derecho.

De ahí que el fundamento para la inserción de temas de carácter económico dentro de una Constitución sea el sometimiento al valor de la justicia de las decisiones económicas que incidan en la vida social, en la promoción y tuitividad de los derechos fundamentales de la persona, y en el aseguramiento del bien común. En buena cuenta, la finalidad de tal incorporación normativa es enfatizar la idea de que toda economía colectiva debe cumplir mínimos supuestos de justicia. (STC. Exp. N. ${ }^{\circ} 0008-2003-A l / T C, 2003$, fundamento jurídico 8)

Ha sido destacada la importancia de contar con un sistema constitucional económico o Constitución económica; sin embargo, su reconocimiento no fue pacífico y, frente a posturas oposicionistas, el Tribunal Constitucional señaló: 
No es ajeno a este Colegiado el hecho de que cierto sector de la doctrina y de la propia comunidad económica cuestione la conveniencia de incluir en el texto constitucional normas orientadas a establecer las pautas básicas sobre las que debe fundarse el régimen económico de una sociedad. $Y$ aunque no se expone de manera categórica, no es difícil deducir que, en dichas críticas, subyace el temor al supuesto riesgo de restar flexibilidad a un régimen que, desde tal perspectiva, debe estar sometido al imperio del mercado. Al respecto, es necesario enfatizar que el verdadero riesgo sería que la recomposición de las desigualdades sociales y económicas quede librada a la supuesta eficiencia de un mercado que, por razones de distinta índole, se instituye desde una indiscutible disparidad entre los distintos agentes y operadores de la economía. En efecto, así como el excesivo poder político del Estado ha sido siempre un riesgo para la libertad humana, de la misma forma el poder privado propiciado por una sociedad corporativa constituye una grave y peligrosa amenaza para la regencia del principio de justicia [cursivas añadidas]. (STC. Exp. N. ${ }^{\circ} 0008-2003-\mathrm{Al} / \mathrm{TC}, 2003$, fundamento jurídico 3)

\section{Empresario, empresa, actividad económica}

La determinación de la economía social de mercado en la Constitución de 1979 como régimen económico, su mantenimiento en la Carta de 1993, la incorporación del término empresa y el uso del término empresario generaron una corriente modificadora o derogatoria de normas consideradas vetustas, como el Código de Comercio peruano, del cual se señaló lo siguiente:

El actual Código de Comercio (1902) acaba de cumplir cien años de vigencia; sin embargo, de su estructura y contenido original queda muy poco, por cuanto su desfase con la realidad, su incompatibilidad con nuevas figuras de naturaleza civil y comercial, entre otros, obligó en su momento a introducirle múltiples modificaciones sustanciales mediante leyes especiales, tales como la Ley de Sociedades Mercantiles N. ${ }^{\circ} 16123$ (ahora Ley General de Sociedades N. ${ }^{\circ} 26887$ ); la Ley General de Instituciones Bancarias, Financieras y de Seguros (ahora Ley General del Sistema de Financiero y del Sistema de Seguros y Orgánica de la Superintendencia de Banca y Seguros); la Ley de Títulos Valores N. ${ }^{\circ} 16587$ (ahora Ley de Títulos Valores N. ${ }^{\circ}$ 27287); la Ley Procesal de Quiebras N. ${ }^{\circ} 7565$ (posteriormente Ley de Reestructuración Empresarial y ahora la Ley de Reestructuración Patrimonial); la Ley del Registro Fiscal de Ventas a Plazos, entre otras, tal vez de menor rango, pero igual de importantes, por cuanto han contribuido y siguen contribuyendo al desarrollo comercial de nuestro país. (Cámara de Comercio de Lima, 2002)

Así, para derogar o actualizar el Código de Comercio, se crearon comisiones para elaborar proyectos desde el año 1996 (Ley N. ${ }^{\circ} 26595$ del 20 de abril de 1996). En 1998, se elaboró el Anteproyecto de Ley General de la Empresa, que posteriormente se convirtió en el Anteproyecto de la Ley Marco del Empresariado (publicado el 6 de mayo de 1999). Luego, en el año 2001, este fue acogido por la congresista Rosa Florián Cedrón y presentado como Proyecto N. ${ }^{\circ}$ 220-2001-CR. A este texto se le realizaron algunos ajustes que 
dieron lugar a una Propuesta Alternativa al Proyecto N. 220-2001-CR, Ley Marco del Empresariado (Congreso de la República del Perú, 2001), y allí terminó el esfuerzo de crear un derecho empresarial como disciplina conceptual autónoma que comprendiera al derecho comercial, al derecho societario y al derecho cambiario, entre otros, cuyo objeto de estudio y regulación sean principalmente la empresa, el empresario, la actividad empresarial y el riesgo. Si bien no tenemos una Ley Marco del Empresariado, es conveniente su estudio, ya que hay muchos aspectos que no están en las leyes, pero sí se manifiestan en la actividad económica nacional.

Al no haber surgido el derecho empresarial como disciplina jurídica, esto es, con sus propios términos, categorías, lenguaje, cuerpo normativo y método, siguiendo la calificación jurídica del acto de comercio y el comerciante, la empresa vendría a ser el objeto del derecho y el empresario el sujeto de derecho. Si bien no es un tema que se vaya a desarrollar en este artículo, cabe indicar que para describir jurídicamente a la "empresa" existen teorías: unas que le reconocen subjetividad propia señalándola, por ejemplo, como sociedad anónima (y la confunden con el empresario, que es el sujeto de derecho); y otras que responden a criterios objetivos, esto es, empresa como actividad, como objeto o producción, entre otras. Sin embargo, se advierte que el término económico empresa se usa en el ámbito jurídico como "sociedad mercantil" tanto por personas legas como por los miembros de la comunidad jurídica, lo que implica que se sigue la teoría de la subjetividad consciente o inconscientemente. Con ello se genera un problema jurídico, ya que, si empresa es una sociedad mercantil, entonces, empresa es el sujeto de derecho, y bien sabemos que el sujeto de derecho es el empresario. Ahora bien, para tratar de resolver este problema, a partir de la lectura del trabajo del maestro Carlos Fernández Sessarego, se identificó que la razón del "vértice" sociedad y empresa como sujeto de derecho encuentra explicación si se tienen en cuenta dos "lados" de la persona jurídica-sociedad mercantil: el lado del empresario, que viene a ser el "cuerpo", y el lado de la empresa, que sería el "alma" (Guerra-Cerrón, 2018). Esta combinación es útil y determinante para reconocer un componente esencial en la actividad económica y un imperativo constitucional, y la alusión no es solo a la ética empresarial, sino a la responsabilidad social.

\section{ECONOMÍA SOCIAL DE MERCADO O ECONOMÍA DE MERCADO CON RESPONSABILIDAD SOCIAL}

En el artículo 58 de la Constitución Política, se señala que el régimen económico nacional es el de la economía social de mercado. Esa es la forma como siempre nos referimos a ella, no solo en el Perú, sino también en cuanto texto podemos leer sobre este tema. El término "economía social de mercado" nació en el contexto de la Alemania de la posguerra, sobre la base de valores como libertad, justicia y solidaridad, así como 
propósito de eficiencia del mercado, Estado mínimo y Estado fuerte, entre otros. Su creación se atribuye a Walter Eucken (1891-1950), Leonhard Miksch (1901-1950), Franz Böhm (1895-1977), Alfred Müller-Armack (1901-1978), Wilhelm Röpke (1899-1966) y Alexander Rüstow (1885-1963), reconocidos como representantes del humanismo económico y social. Entre ellos destaca Alfred Müller-Armack, con su concepto de economía social de mercado: "La esencia de la economía social de mercado consiste en combinar el principio de libertad en el mercado con el de compensación social".

Cabe preguntarse si se trata de un sistema o modelo económico, teniendo en cuenta que los sistemas económicos que conocemos son el social o de planificación centralizada y el liberal o de mercado, pues se advierte que, como no es ni uno ni otro, entonces, podría señalarse que ha surgido un tercer sistema o que se ha construido un modelo con la combinación de principios y normas de cada uno de los sistemas antes mencionados.

Para esclarecer este asunto, resulta de gran relevancia la opinión de Kurth SchultzeRhonhof (2001), quien, primero, expone la dificultad en la comprensión de lo económico y social de la siguiente manera:

El término de economía social contiene en sí apariencias contradictorias. El evidente contraste entre lo económico y lo social hace que el concepto de economía social sea difícil de entender, y, en verdad, no me sorprende que la gran mayoría de los agentes económicos y de los responsables de la política nacional en el Perú sigan confundidos por esta evidente dicotomía entre estos conceptos. (p. 29)

Y, en segundo lugar, señala, lo que puede considerarse que "rompe esquemas" y que pone en "tela de juicio": la denominación economía social de mercado (traducida del idioma alemán) que usamos de manera general es una mala traducción:

El importante acento está en la palabra Marktwirtschaft, es decir, el concepto de economía de mercado - Marktwirtschaft- contrastado con el concepto de economía centralmente planificada, Planwirtschaft. A este concepto de economía de mercado, los economistas alemanes le agregaron el calificativo de responsabilidad social. Si se hubiera hecho la traducción correctamente, se hubiera hablado de economía de mercado opuesta a economía centralmente planificada, agregando el calificativo de social, es decir, de responsabilidad social. El término, por lo tanto, para nosotros, en el futuro, podría ser "economía de mercado con responsabilidad social" [cursivas añadidas]. (p. 30)

Si tenemos en cuenta que existen dos sistemas económicos: el de planificación centralizada y el de mercado, entonces, no podría hablarse de una economía social, porque vendría a ser lo mismo que el de planificación centralizada. Por lo tanto, es razonable que se haya creado un modelo a partir del sistema de mercado, cuyos componentes son principios sociales para evitar desigualdades y promover el equilibrio económico entre las personas. Un componente esencial, aunque no se encuentre expresamente señalado en la Constitución económica, es la responsabilidad social; por tanto, la expresión 
apropiada es "economía de mercado con responsabilidad social" y la coherencia de este planteamiento se verificaría en lo desarrollado por el Tribunal Constitucional:

En una economía social de mercado, tanto los particulares como el Estado asumen deberes específicos; en el primer caso, el deber de ejercitar las referidas libertades económicas con responsabilidad social [cursivas añadidas], mientras que, en el segundo, el deber de ejercer un rol vigilante, garantista y corrector, ante las deficiencias y fallos del mercado, y la actuación de los particulares.

La Constitución reserva al Estado, respecto del mercado, una función supervisora y correctiva o reguladora, en el entendido [de] que, si bien el ejercicio de la libertad de los individuos en el mercado debe ser garantizada plenamente, también es cier to que debe existir un Estado que, aunque subsidiario en la sustancia, mantenga su función garantizadora y heterocompositiva. (STC. Exp. N. ${ }^{\circ} 1963-2006-A A / T C$, 2006, fundamentos jurídicos 3-9)

\section{Los principios generales y la responsabilidad social}

La responsabilidad social está implícita en cada uno de los principios generales en la Constitución económica. En tal sentido: "La interpretación interdependiente de la institucionalidad constitucional permitirá aprehender adecuadamente el contenido y la finalidad del modelo económico establecido en la Constitución. Para ello, es preciso determinar previamente los principios básicos de la estructura del sistema constitucional económico" (STC. Exp. N. ${ }^{\circ}$ 0008-2003-Al/TC, 2003, fundamento jurídico 5). En la tabla 1 se pueden leer los principios y se advierte la exigencia de la responsabilidad social.

Tabla 1

Principios básicos de la estructura del sistema constitucional económico

\begin{tabular}{ll}
\hline \multicolumn{1}{c}{ Principios } & \multicolumn{1}{c}{ Contenido e inferencia } \\
\hline $\begin{array}{l}\text { Artículo } 58 \\
\text { Iniciativa privada libre }\end{array}$ & - La libertad se garantiza, en la medida que se realice con responsabilidad \\
Rol del Estado & - Estado fuerte en el cumplimiento de deberes esenciales con RS. \\
\hline Artículo 59 & Estado fuerte, garante de libertades de trabajo, de empresa, comercio e \\
Libertades & industria. Estimula la creación de riqueza, evita cualquier desigualdad y \\
Rol del Estado & promueve las pequeñas empresas en todas sus modalidades. Actuación \\
& con RS. \\
\hline Artículo 60 & - Coexistencia de diversas formas de propiedad y de empresa. En todos los \\
Pluralismo económico & casos, la actuación debe ser con RS. \\
Subsidiariedad del Estado & - Estado mínimo, que ejerce actividad empresarial solo autorizado por ley \\
& expresa por razón de alto interés público o de manifiesta conveniencia \\
& nacional. Podría entenderse un supuesto cuando el particular no actúa \\
& con RS.
\end{tabular}


(continuación)

\begin{tabular}{|c|c|}
\hline $\begin{array}{l}\text { Artículo } 61 \\
\text { Libre competencia }\end{array}$ & $\begin{array}{l}\text { Estado fuerte, que facilita y vigila la libre competencia (RS). } \\
\text { - Prohibición de abuso de posición de dominio o monopólica. } \\
\text { - Prohibición de monopolio de la prensa, la radio, la televisión y los demás } \\
\text { medios de expresión y comunicación social. }\end{array}$ \\
\hline $\begin{array}{l}\text { Artículo } 62 \\
\text { Libertad de contratación }\end{array}$ & $\begin{array}{l}\text { Libertad de contratar y contractual (con quién y en qué) con RS. } \\
\text { "Contrato ley entre las partes". }\end{array}$ \\
\hline $\begin{array}{l}\text { Artículo } 63 \\
\text { Libertad de inversión } \\
\text { Libertad de comercio } \\
\text { exterior }\end{array}$ & $\begin{array}{l}\text { Estado fuerte (RS), que facilita la inversión nacional y extranjera. } \\
\text { - La producción de bienes y servicios y el comercio exterior son libres. } \\
\text { - Solución de controversias por arbitraje y Poder Judicial. }\end{array}$ \\
\hline $\begin{array}{l}\text { Artículo } 64 \\
\text { Libre tenencia de moneda } \\
\text { extranjera }\end{array}$ & $\begin{array}{l}\text { - Estado fuerte (RS), que garantiza la libre tenencia y disposición de moneda } \\
\text { extranjera. }\end{array}$ \\
\hline $\begin{array}{l}\text { Artículo } 65 \\
\text { Protección del consumidor } \\
\text { o usuario }\end{array}$ & $\begin{array}{l}\text { Estado fuerte (RS), que defiende el interés de los consumidores y usuarios. } \\
\text { Garante del derecho de información sobre los bienes y servicios que se } \\
\text { encuentran a su disposición en el mercado. } \\
\text { Deber esencial del Estado de velar particularmente por la salud y la } \\
\text { seguridad de la población (RS). }\end{array}$ \\
\hline
\end{tabular}

Elaboración propia

Será un Estado fuerte cuando, estableciendo el marco legal adecuado y garantizando la libertad de los privados en el ejercicio de su actividad económica, pueda cumplir con sus deberes esenciales para promover el bienestar general, de manera que asegure la combinación de libertad y compensación social. Por su parte, será un Estado mínimo respecto a la actuación en la actividad empresarial que corresponde a los particulares, salvo que sea indispensable para el cumplimiento de sus deberes esenciales. El sector privado debe responder a ese reconocimiento de libertad de empresa, industria y comercio con una actividad económica con responsabilidad social.

\section{Responsabilidad social}

Un tema recurrente en la investigación para optar grados de magíster o doctor en Derecho es el de responsabilidad social (RS) en diferentes modalidades: RS universitaria, RS estatal, RS empresarial o RS corporativa, entre otros; y para cada modalidad habría un contenido o propósito distinto. Entre las pocas leyes en las que se encuentra un concepto de RS, se encuentra la Ley Universitaria, Ley N. ${ }^{\circ} 30220$ (2014), artículo 24:

La responsabilidad social universitaria es la gestión ética y eficaz del impacto generado por la universidad en la sociedad debido al ejercicio de sus funciones: académica, de investigación y de servicios de extensión y participación en el desarrollo nacional en sus diferentes niveles y dimensiones; incluye la gestión del impacto producido por las relaciones entre los miembros de la comunidad 
universitaria, sobre el ambiente, y sobre otras organizaciones públicas y privadas que se constituyen en partes interesadas. La responsabilidad social universitaria es fundamento de la vida universitaria, contribuye al desarrollo sostenible y al bienestar de la sociedad. Compromete a toda la comunidad universitaria.

Reproducimos este artículo, ya que describe una serie de acciones y pautas. Lo principal es que no se trata de una facultad, sino de un imperativo, esto es, se obliga a que las universidades actúen con responsabilidad social y, para ello, tienen que diseñar sus programas de actuación. Nótese que la actividad universitaria no es una actividad económica (aunque también la pueda desarrollar como persona jurídica sin fines de lucro), sino una actividad educativa. Tal vez por ello la responsabilidad social en este caso no es solo una facultad.

No ocurre lo mismo con la modalidad de RS empresarial y RS corporativa, que carecen de un desarrollo o precisión. No se entiende cómo un componente esencial del régimen económico del Perú pueda ser facultativo, esto es, que se puede cumplir o no, y que no exista disposición jurídica de desarrollo respecto a esta esencialidad propia de la economía social de mercado.

Si bien existe una norma técnica ISO 26000:2010 que "[...] ofrece armonizadamente una guía global pertinente para las organizaciones del sector público y privado de todo tipo, basada en un consenso internacional entre expertos representantes de las principales partes interesadas, por lo que alienta la aplicación de mejores prácticas en responsabilidad social en todo el mundo" (Organización Internacional de Estandarización [ISO], 2010, p. 3), es facultativa. Efectivamente, a pesar de que la norma ayudaría a "[...] operar de la manera socialmente responsable que la sociedad exige cada vez más. ISO 26000 contiene guías voluntarias [cursivas añadidas], no requisitos, y, por lo tanto, no es para utilizar como una norma de certificación como la ISO 9001:2008 y la ISO 14001:2004" (ISO, 2010, p. 4). Esta norma técnica fue aprobada por Indecopi en noviembre del año 2010.

\section{LA RESPONSABILIDAD SOCIAL EN LA ACTIVIDAD ECONÓMICA}

La afirmación de Milton Friedman (1970) respecto a que la "responsabilidad social de la empresa es incrementar sus beneficios", esto es, solo obtener ganancias, puede encontrar justificación si el concepto de "social" está delimitado a la finalidad económica de una sociedad mercantil en términos societarios, ya que en el Anteproyecto de la Ley Marco del Empresariado, antes mencionado, se señala que "[l]a finalidad lucrativa está implícita en todo acto empresarial, porque el empresario debe cubrir costos y obtener un remanente que permita la continuidad de su actividad económica. Si no cubre costos y logra un margen de beneficio razonable, estaría condenado a quebrar" (Congreso de la República del Perú, 2001). Efectivamente, cuando se habla de "empresa-sociedad" como 
célula fundamental de la vida económica, se alude al objeto social, a la creación de valor, a generar utilidades y promover una maximización de beneficios para sus accionistas. Sin embargo, este concepto de "social" hoy es insuficiente y hasta inconveniente, más aún si se deben tener presentes los preceptos de la Constitución económica que, como se ha señalado de manera reiterativa, tienen como componente esencial a la responsabilidad social. Así:

La responsabilidad social de la empresa forma parte del negocio mismo, no es una actividad separada [cursivas añadidas], es la conducción del negocio en un ámbito más amplio que el determinado por la maximización de beneficios para los accionistas o dueños. A través de estas prácticas responsables, llevadas a cabo como un elemento más de gestión de la empresa, se pueden conseguir mejoras competitivas que dan lugar a mayores beneficios a la vez que se contribuye a crear una sociedad mejor. De este modo la empresa no solo se convierte en un instrumento de desarrollo económico, sino también en un instrumento de desarrollo social. (Vives y Peinado-Vara, 2003, p. 10)

La expresión de que "la responsabilidad social forma parte del negocio mismo" resulta coherente con lo antes señalado respecto a que la empresa es el "alma" de la persona jurídica-sociedad mercantil (cuerpo), que realiza actividad económica (sin fines de lucro y con finalidad económica). Si se piensa en los consumidores, el "alma" o la responsabilidad social sería una actuación en la que no solo se busque rentabilidad del negocio, sino actuar en interés de los consumidores y de la comunidad en general: proporcionar productos o servicios necesarios a precios y calidades honestos, ya que con ello se debe atender a la subsistencia y desarrollo integral de las personas. Dicho en términos societarios, la actividad societaria y las prácticas de buen gobierno corporativo no deben tener como propósito el bienestar solo de los stakeholders desde un punto de vista financiero, sino de bienestar general e integral, dejar la percepción intramuros para trascender y dar resultados a la demanda de compensación social, propia de la economía de mercado con responsabilidad social.

La citada expresión de que "la responsabilidad social forma parte del negocio mismo" define todo el panorama, puesto que aquello que ha sido considerado desde siempre como una facultad tendría la imperiosa necesidad de ser regulado para que el régimen económico nacional se realice plenamente, ya que hoy, como bien señalan algunas personas, lo que tenemos no pasaría de ser un sistema de mercado puro (porque no se materializa la responsabilidad social).

Si tenemos en cuenta que la palabra responsabilidad proviene de respondere, que a su vez significa "estar obligado", las preguntas que pueden hacerse son estas: ¿a qué se encuentra obligada una organización económica? y ¿cuál es el punto de partida para determinarlo? Para dar respuesta a esas preguntas, se toma como referencia el concepto 
contenido en el Proyecto Alternativo al Anteproyecto de la Ley Marco del Empresariado, Libro I: De la empresa, artículo 9, en el que se proyecta a la empresa como una

[...] organización económica dedicada a la producción, transformación o comercialización de bienes, o a la prestación de servicios, socialmente responsable [cursivas añadidas], es decir que su objetivo y acción no se circunscriben solo a los términos económicos, sino a su involucramiento con la sociedad, su comunidad y con su propio entorno [cursivas añadidas]. Puede ser organizada por persona natural o jurídica. (Congreso de la República del Perú, 2001)

Responsabilidad social implica involucramiento con el entorno: interno y externo. Y ello demanda compromiso, comprensión, inclusión y participación activa en determinada área o problema. Esto no es otra cosa que el componente en la definición de economía social de mercado: "combinar el principio de libertad en el mercado con el de compensación social".

Se me viene a la mente la importancia que se ha dado a los programas de cumplimiento (compliance) por tener un fundamento y exigencia legal; sin embargo, respecto a la responsabilidad social, que es un mandato constitucional, no hay proyectos ni desarrollos. En una oportunidad, en una charla acerca de este tema, se señaló que "una chocolatada en Navidad para un colegio o un asilo" no estaba dentro del marco de la responsabilidad social, aunque tal vez sí de la responsabilidad social empresarial, lo que puede llevar a determinar que lo que se entiende como responsabilidad social en el ámbito empresarial privado responde a un enfoque errado y no se condice con el deber constitucional.

\section{COLOFÓN}

No cabe duda de que la filosofía en la Constitución económica y los principios del régimen económico nacional tienen como componente esencial a la responsabilidad social, por lo que lo apropiado es referirse a la "economía de mercado con responsabilidad social", en el que el valor agregado "social" puede ser explicado según lo señalado por el Tribunal Constitucional:

[...] se define aquí desde tres dimensiones: como mecanismo para establecer legítimamente algunas restricciones a la actividad de los privados; como una cláusula que permite optimizar al máximo el principio de solidaridad, corrigiendo las posibles deformaciones que pueda producir el mercado de modo casi "natural", permitiendo, de este modo, un conjunto de mecanismos que permitan al Estado cumplir con las políticas sociales que procuren el bienestar de todos los ciudadanos; $y$, finalmente, como una fórmula de promoción del uso sostenible de los recursos naturales para garantizar un ambiente equilibrado y adecuado al desarrollo de la vida. (STC. Exp. N. ${ }^{\circ}$ 0048-2004-PI/TC-Lima, 2005, fundamento jurídico 16) 
En consecuencia, el bienestar general como aspiración tendrá sustento en la medida que ambos sujetos: el Estado y el empresariado actúen en las funciones y actividades que les competen con responsabilidad social, no como acto especial, sino como un acto natural por imperio de la Constitución económica.

Se puede dudar de lo manifestado por Schultze-Rhonhof (2001) respecto a que la correcta denominación del régimen económico es economía de mercado con responsabilidad social, apreciación que se considera apropiada, debido a que tiene un sustento lógico y acorde con el contenido de los sistemas económicos vigentes: de mercado y de planificación centralizada, así como con los principios y finalidades de cada uno. Pero téngase presente que "la duda es la madre del descubrimiento" y esta puede servir para descubrir que la ineficacia que se atribuye al régimen económico nacional no es por su filosofía y contenido, sino que puede responder a una simple y mala traducción, que sería el "escudo" para evadir el imperativo de actuación con responsabilidad social.

\section{REFERENCIAS}

Cámara de Comercio de Lima. (2002). Propuesta Alternativa Proyecto Ley Marco del Empresariado. En Propuesta Alternativa al Proyecto N. ${ }^{\circ} 220-2001-C R$, Ley Marco del Empresariado. Recuperado de https://www.perucamaras.org.pe/pdf/2/1_1_ Revision_del_Proyecto_de_Ley_Marco_del_Empresariado.pdf

Congreso de la República del Perú. (1998). Ley Marco del Empresariado. Anteproyecto y exposición de motivos. Recuperado de http://www4.congreso.gob.pe/ comisiones/1998/r_codigos/codigo31.htm

Congreso de la República del Perú. (2001). Anteproyecto. Proyecto de Ley Marco del Empresario. Recuperado de http://www2.congreso.gob.pe/sicr/tradocestproc/ clproley2001.nsf/pley/20F617E50F3128A105256D25005D31D8?opendocument

D’Auria, A. (2012). Teoría y crítica del Estado. Buenos Aires: Eudeba.

Friedman, M. (13 de septiembre de 1970). La responsabilidad social de la empresa es incrementar sus beneficios. The New York Times Magazine. Recuperado de http:// perso.unifr.ch/derechopenal/assets/files/articulos/a_20150908_04.pdf

Guerra-Cerrón, M. E. (2018). La empresa: "un punto controvertido" entre el derecho y la economía. Athina. Revista de Derecho de los alumnos de la Universidad de Lima, 14, pp. 335-356.

Gutiérrez Camacho, W. (2013). Constitución económica, iniciativa privada y economía social de mercado. En La Constitución comentada (2. ${ }^{a}$ ed., aumentada y revisada, tomo II, pp. 13-26). Lima: Gaceta Jurídica. 
Organización Internacional de Estandarización. (2010). ISO 26000 visión general del proyecto. Recuperado de https://www.iso.org/files/live/sites/isoorg/files/ archive/pdf/en/iso_26000_project_overview-es.pdf

Rubio Correa, M. (2006). El Estado peruano según la jurisprudencia del Tribunal Constitucional. Lima: Pontificia Universidad Católica del Perú, Fondo Editorial.

Schultze-Rhonhof, K. (2001). Economía social de mercado: ¿visión para el siglo xxı? En La economía social del mercado (pp. 28-52). Lima: Fundación Hanns Seidel.

Sentencia recaída en el Expediente N. 0008-2003-Al/TC-Lima. (2003). Tribunal Constitucional del Perú. Recuperado de https://www.tc.gob.pe/jurisprudencia /2003/00008-2003-Al.html

Sentencia recaída en el Expediente N. 5854-2005-PA/TC-Piura. (2005). Tribunal Constitucional del Perú. Recuperado de https://www.tc.gob.pe/tc/private/ adjuntos/cec/gaceta/gaceta/jurisprudencia/05854-2005-AA.html

Sentencia recaída en el Expediente N.º 0048-2004-PI/TC-Lima. (2005). Tribunal Constitucional del Perú. Recuperado de https://tc.gob.pe/jurisprudencia/2005/ 00048-2004-Al.pdf

Sentencia recaída en el Expediente N. 1963-2006-AA/TC-Piura. (2006). Tribunal Constitucional del Perú. Recuperado de https://tc.gob.pe/jurisprudencia/2007/ 01963-2006-AA.pdf

Vives, A., y Peinado-Vara, E. (2003). Introducción. Ser socialmente responsables nos conviene a todos. En A. Vives y E. Peinado-Vara (Eds.), La responsabilidad social de la empresa como instrumento de competitividad. Anales (pp. 10-12). Recuperado de https://publications.iadb.org/publications/spanish/document/ La-Responsabilidad-Social-de-la-Empresa-como-Instrumento-de-Competiti vidad-Anales.pdf 